\title{
Anatomic Repair of Congenitally Corrected Transposition: Reappraisal of Eligibility Criteria
}

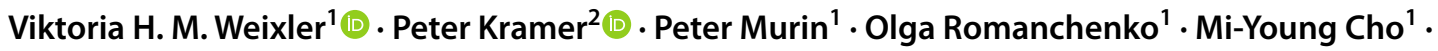 \\ Stanislav Ovroutski ${ }^{2} \cdot$ Michael Hübler ${ }^{1} \cdot$ Felix Berger $^{2} \cdot$ Joachim Photiadis $^{1}$
}

Received: 21 November 2021 / Accepted: 3 February 2022 / Published online: 11 February 2022

(c) The Author(s) 2022

\begin{abstract}
Several criteria to identify suitable candidates for anatomic repair in congenitally corrected transposition (cc-TGA) have been proposed. The purpose of this study was to critically re-evaluate adequacy of these recommendations in our patient cohort. All cc-TGA patients undergoing anatomic repair between 2010 and 2019 were reviewed. Evaluated eligibility criteria for repair included age $\leq 15$ years, LV mass index $\geq 45-50 \mathrm{~g} / \mathrm{m}^{2}, \mathrm{LV}$ mass/volume ratio $>0.9-1.5$ and systolic LV to right ventricle pressure ratio $>70-90 \%$ among others. Repair failure was defined as postoperative early mortality or LV dysfunction requiring mechanical circulatory support. Twenty-five patients were included (median [interquartile range] age at surgery 1.8 years [0.7;6.6]; median postoperative follow-up 3.2 years [0.7;6.3]). Median preoperative LV ejection fraction was $60 \%$ [56;64], indexed LV mass $48.5 \mathrm{~g} / \mathrm{m}^{2}$ [43.7;58.1] and $\mathrm{LV}$ mass/volume ratio 1.5 [1.1;1.6], respectively. A total of 12 patients (48\%) did not meet at least one of the previously recommended criteria, however, all but two patients (92\%) experienced favorable early outcome. Of 7 patients (28\%) with indexed LV mass $<45 \mathrm{~g} / \mathrm{m}^{2}, 6$ were successfully operated. There were two early repair failures (8\%) with LV dysfunction: one patient died and one required mechanical circulatory support but recovered well. Surgery was performed successfully in patients with LV mass and volume Z-scores as low as -2 and -2.5 , respectively. Anatomic correction for cc-TGA can be performed with excellent early outcome and is feasible even in patients with LV mass below previously recommended cut-offs. The use of LV mass and volume Z-scores might help to refine eligibility criteria.
\end{abstract}

Keywords Congenital heart disease $\cdot$ Congenital heart surgery $\cdot$ Great vessel anomaly $\cdot$ Ventricular septal defect $\cdot$ Arterial switch operation $\cdot$ Echocardiography

\section{Abbreviations}

ASD Atrial septal defect

ASO Arterial switch operation

cc-TGA Congenitally corrected transposition of the great arteries

EF Ejection fraction

LV Left ventricle

Viktoria H. M. Weixler and Peter Kramer have contributed equally to this article.

Peter Kramer

kramerpeter@dhzb.de

1 Department of Congenital Heart Surgery, German Heart Center Berlin, Augustenburger Platz 1, 13353 Berlin, Germany

2 Department of Congenital Heart Disease/Pediatric Cardiology, German Heart Center Berlin, Augustenburger Platz 1, 13353 Berlin, Germany
LVEDV Left ventricular end-diastolic volume

LVOTO Left ventricular outflow tract obstruction

MV Mitral valve

PAB Pulmonary artery banding

RV Right ventricle

TV Tricuspid valve

VSD Ventricular septal defect

\section{Introduction}

Congenitally corrected transposition of the great arteries (cc-TGA) is a rare and complex congenital malformation, accounting for approximately $0.05 \%$ of all congenital heart defects [1]. Untreated, natural history is often accompanied by progressive failure of the systemic right ventricle (RV), tricuspid valve (TV) regurgitation, arrhythmia as well as 
sudden cardiac death with approximately $50 \%$ of the patients dying before the age of 40 years $[1,2]$.

Different types of anatomic repair aiming for correction of the double discordance have been proposed, combining an atrial stage switch (Senning or Mustard procedure) together with either arterial switch operation (ASO) as double switch operation or, in case of relevant left ventricular outflow tract obstruction (LVOTO) and ventricular septal defect (VSD), as intra-ventricular rerouting by means of a Rastelli procedure [3]. More recently, variations of aortic root translocations such as the Nikaidoh or the half-turned truncal switch/en bloc rotation procedures have been introduced, improving LVOT geometry and supposedly avoiding the concern of recurrent LVOTO [4-6].

Promising early outcomes after anatomic correction have been reported [7-10], however, there is uncertainty regarding the crucial prerequisites that have to be met in order to ensure that the subpulmonary morphologic left ventricle (LV) will sustain the workload of the systemic circulation after surgery. Several studies have proposed various selection criteria for the evaluation of cc-TGA patients' eligibility for anatomic repair. Suggested criteria mostly focus on LV pressure load and muscle mass, however their appropriateness has not been broadly validated [11-13]. Moreover, it remains unclear, to what extent such criteria apply to cc-TGA patients with an unrestrictive VSD. Although in general these patients might be perceived as suitable for anatomical correction since the morphological LV is supposedly "well-trained" due to continuous systemic pressure load and volume load, it is not self-evident that this will naturally translate into sufficient ventricular size or muscle mass development [14].

The purpose of this study was to re-evaluate previously recommended criteria for cc-TGA in our institutional cohort in respect to their adequacy in identifying patients suitable for anatomic correction.

\section{Patients and Methods}

\section{Study Design}

We performed a retrospective analysis of all cc-TGA patients that underwent anatomic repair from 01/2010 to 12/2019 in our institution. No physiologic repair was performed at our institution during the study period. The study was approved by the institutional ethics committee (EA2/165/19), the requirement of written consent was waived.

\section{Surgical Procedures}

Various procedures representing anatomic repair have been employed in our institution as deemed technically feasible and promising favorable surgical results according to individual cardiac morphology (Fig. 1). Correction of atrio-ventricular discordance by atrial stage switch was performed as Senning or Mustard procedure. Correction of ventriculoarterial discordance was carried out as ASO, solely or in combination with LVOTO resection, Rastelli procedure or aortic root translocation, either performed as classical Bex-Nikaidoh procedure or as en bloc rotation (half-turned truncal switch), respectively [4-6, 14]. In patients with significant LVOTO, aortic root translocation was the preferred surgical approach, if feasible according to coronary anatomy and pulmonary valve function and dimension. Patients with non-existing/restrictive ventricular septal defect (VSD) underwent initial pulmonary artery banding (PAB) to train the morphological LV by increasing afterload. Additionally, an atrial septal defect was created in cases without preexisting atrial communication during the more recent study period to increase LV preload. In patients with a large VSD

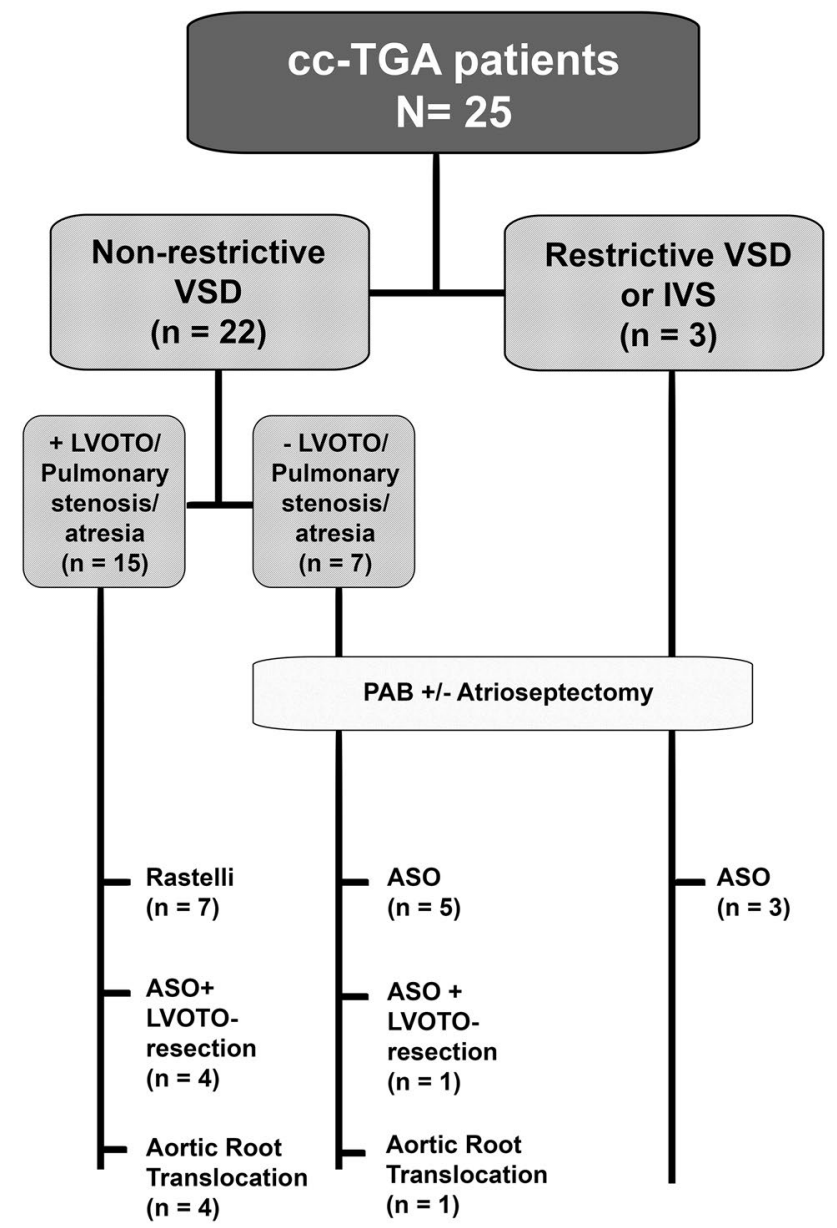

Fig. 1 Description of sthe study cohort. ASO arterial switch operation, $c c-T G A$ congenitally corrected transposition of the great arteries, IVS intact ventricular septum/ no ventricular septal defect, LVOTO left ventricular outflow tract obstruction, $P A B$ pulmonary artery banding, $V S D$ ventricular septal defect 
and non-existing/insufficient LVOTO, PAB was established to protect the pulmonary vasculature until correction. A systemic-to-pulmonary shunt was placed in patients with severe restriction of pulmonary blood flow and desaturation prior to surgical correction.

\section{Criteria for Anatomic Repair and Outcome Definitions}

The following previously recommended criteria to identify suitable candidates for anatomic repair were evaluated in our patient cohort: age $\leq 15$ years, LV ejection fraction $(\mathrm{EF})>55 \%$, mitral valve $(\mathrm{MV})$ regurgitation $\leq$ mild, $\mathrm{LV}$ mass index $\geq 45-50 \mathrm{~g} / \mathrm{m}^{2}, \mathrm{LV}$ mass/volume ratio $>0.9-1.5$ and systolic LV/RV pressure ratio $>70-90 \%$, $[8,11-13,15$, 16].

Data pertaining to these criteria were retrieved from medical charts. Additional data recorded and analyzed included preoperative demographics, functional status, morphological details as well as prior palliative surgical procedures; intraoperative data as well as early postoperative complications were also extracted. Primary endpoint was early repair failure which was defined as early mortality (30-day mortality) and/or postoperative LV failure requiring mechanical circulatory support. Secondary endpoints were late repair failure defined as severe impairment of LV function and/or heart failure corresponding to NYHA/modified Ross classification [17] functional class $\geq$ III at last follow-up; additional secondary endpoints included mid-term mortality, requirement of reoperation and/or catheter reintervention.

\section{Echocardiographic Analysis}

Patients' digitally archived echocardiograms at baseline and last follow-up were analyzed offline with a vendor-specific software (EchoPACTM version 203; General Electric Vingmed Ultrasound AS, Horten, Norway). Measurements were performed according to current recommendations [18]. Atrioventricular or semilunar valve regurgitation was graded semi-quantitatively as absent/trace, mild, moderate or severe according to color Doppler jet area and vena contracta width. Speckle tracking analysis with measurement of RV and LV global systolic strain was performed in standard apical fourchamber view greyscale images [19, 20]. $Z$-scores for echocardiographic measurements were calculated according to published regression equations [19, 21-23]. Z-scores for RV fractional area change were estimated from published mean values and standard deviations [24].

\section{Statistical Analysis}

Variables are presented as median [interquartile range] for continuous variables or as frequency $(\%)$ for categorical data.
Comparisons between unpaired groups were performed by nonparametric Mann-Whitney $U$ test or one-way ANOVA with Bonferroni post-hoc test according to number of groups compared. Paired variables were compared using Wilcoxon signed rank test. Freedom from death and reoperations were analyzed using Kaplan-Meier time-to-event models and logrank test was used to compare groups. Multivariable binary logistic regression analysis was performed to evaluate independent risk factors for primary outcome. Statistical analysis was performed using IBM-SPSS version 24.0 (IBM-SPSS Inc, Armonk, NY) and GraphPad Prism version 8.4.0 (GraphPad Software, Inc., San Diego, CA, USA). $P$-values $<0.05$ were considered statistically significant.

\section{Results}

\section{Baseline Characteristics}

A total of 25 patients underwent anatomic correction in our institution during the study period. Median follow-up was 3.2 years $[0.7 ; 6.3]$. Patient's characteristics are detailed in Table 1. Eighteen patients $(72 \%)$ had undergone prior surgical procedures. PAB was performed at a median age of 2.8 months [1.4;34.9] and median time interval between $\mathrm{PAB}$ and anatomic correction was 9.9 months $[4.9 ; 10.1]$. Preoperatively, heart failure of varying extent was common; most patients were in NYHA/modified Ross classification functional class II $(n=16,64 \%)$, seven $(28 \%)$ were in class III and only two patients (8\%) were asymptomatic (class I).

\section{Preoperative Invasive and Echocardiographic Evaluation}

All patients had systemic or near systemic LV pressure load. A non-restrictive VSD was present at the time of anatomic repair in 21 patients (84\%). Four patients (16\%) had mildly reduced LVEF $<55 \%$ with the lowest preoperative LVEF being $50 \%$. Of note, nine patients (36\%) had abnormally low LVEDV $Z$-scores $<-2$. Indexed LV mass was below $45 \mathrm{~g}$ / $\mathrm{m}^{2}$ in seven patients (28\%), however, LV mass $Z$-score was marginally below -2 in only one patient, while the remaining patients had $Z$-scores $>-2$. Only one patient showed more than mild MV regurgitation. RV function was also generally sufficiently preserved. Moderate or severe TV regurgitation was documented in six $(24 \%)$ patients (Table 2, Supplemental Table 1).

\section{Surgical Procedures and Postoperative Complications}

Various surgical procedures were performed as depicted in Fig. 1. Atrial switch was predominantly carried out as Senning procedure $(n=23,92 \%)$ while one patient received a 
Table 1 Baseline patients' characteristics

\begin{tabular}{ll}
\hline Variable & Patients $(N=25)$ \\
\hline Male gender & $16(64 \%)$ \\
Body weight (kg) & $10.2[7.5 ; 20.5]$ \\
Age at surgery (years) & $1.8[0.7 ; 6.6]$ \\
Associated lesions & \\
Non-restrictive VSD & $21(84 \%)$ \\
LVOTO & $11(44 \%)$ \\
Pulmonary stenosis/atresia & $12(48 \%)$ \\
LVOTO \pm pulmonary stenosis/atresia & $15(60 \%)$ \\
Coronary anatomy & \\
1R2LCx & $14(56 \%)$ \\
1RLCx & $4(16 \%)$ \\
1L2CxR & $3(12 \%)$ \\
1LCx2R & $3(12 \%)$ \\
1RL2Cx & $1(4 \%)$ \\
Segmental notation & \\
\{SLL\} & $20(80 \%)$ \\
\{IDD & $5(20 \%)$ \\
Anatomic variations & \\
Dextrocardia & $1(4 \%)$ \\
Persistent left superior vena cava & $1(4 \%)$ \\
TAPVD/PAPVD & $2(8 \%)$ \\
Right-sided aortic arch & $2(8 \%)$ \\
Interrupted inferior vena cava & $1(4 \%)$ \\
Prior palliative procedures & \\
Systemic-to-pulmonary shunt & \\
PAB & $1(40 \%)$ \\
Glenn procedure & \\
VSD closure & \\
Atrioseptostomy & \\
Damus-Kaye-Stansel procedure & \\
\hline
\end{tabular}

Continuous data presented as median [interquartile range]; categorical data are presented as frequency (\%)

LVOTO left ventricular outflow tract obstruction, $P A B$ pulmonary artery banding; TAPVD/PAPVD total/partial anomalous pulmonary venous drainage, $V S D$ ventricular septal defect. Several patients had more than one prior surgical procedure

Mustard procedure and another a hemi-Mustard procedure in conjunction with a bidirectional Glenn anastomosis. A Lecompte maneuver was performed in five patients (20\%) with anterior-posterior relationship of the great arteries. Two patients underwent TV repair and one patient MV repair during anatomic repair. Intraoperative and early postoperative variables are given in Supplemental Table 2. Several patients experienced postoperative complications with dysrhythmias being the most frequent. Three patients (12\%) required pacemaker implantation. No significant differences were noticed in intraoperative/early postoperative characteristics between different surgical techniques or between patients with or without prior PAB (all $P>0.05$ ).

\section{Early Repair Failure}

Early repair failure occurred in two patients (8\%). The first patient died, corresponding to an early mortality rate of $4 \%$, while the second patient suffered from early postoperative LV dysfunction (Supplemental Table 1). The deceased patient (\#10) with a large VSD, relevant LVOTO and significant biventricular hypertrophy was almost 18 years at the time of anatomic correction with no prior palliative procedure. She underwent Senning and aortic root translocation and postoperatively required mechanical circulatory support due to biventricular systolic failure. Unfortunately, she could not be weaned off support and died from multi-organ failure.

The second patient (\#22) underwent PAB shortly after birth due to a large VSD with unrestricted pulmonary blood flow. With a LV mass index of $35.8 \mathrm{~g} / \mathrm{m}^{2}$ (Z-Score - 1.3) he underwent Senning with ASO but could not be weaned from bypass due to severe LV dysfunction. He required mechanical circulatory support in form of extracorporeal membrane oxygenation which was later switched to a ventricular assist device. Myocardial function, however, recovered and the patient could successfully be weaned 3 months postoperatively.

\section{Mid-Term Outcomes}

No late repair failure occurred. Nonetheless, late mortality was $8.3 \%(2 / 24)$ due to re-operation mortality. One patient (\#7) developed severe pulmonary baffle stenosis one year after anatomic correction and died the day before scheduled urgent re-operation from refractory cardiac arrest. The second patient (\#4) showed severe pulmonary heterograft stenosis and additional mild pulmonary venous baffle stenosis requiring complex reoperation 2 years after anatomic repair. He could not be weaned from bypass and required circulatory support. Unfortunately, myocardial function did not recover.

Reoperation rate was $16.6 \%$ (4/24) during mid-term follow-up, including pulmonary venous baffle stenosis repair in two $(8.3 \%)$ and pulmonary valve heterograft replacement in two $(8.3 \%)$ patients, in one of whom additional baffle stenosis repair was performed. One patient $(4.2 \%)$ underwent resection of re-occurring LVOTO after an initial ASO and LVOTO resection. Four patients (16.6\%) required catheter reinterventions with balloon dilatation of the pulmonary arteries. No significant differences regarding frequency of reoperations or re-interventions were found between the different surgical techniques or between patients with or without prior PAB (all $P>0.05$ ).

5-year survival estimate was $84.6 \%$ [95\% CI 59.9;94.9] and 5-year freedom from reoperation rate was $73.4 \%$ [95\% CI 42.0;89.6] in the entire study population. In patients with ASO, 5-year survival rates and 5-year freedom 
Table 2 Echocardiographic and hemodynamic parameters

\begin{tabular}{|c|c|c|}
\hline Variable & Preoperatively $(N=25)$ & Last follow-up $(N=22)$ \\
\hline \multicolumn{3}{|l|}{ RV echocardiographic measurements } \\
\hline $\mathrm{RV}$ diastolic area $\left(\mathrm{cm}^{2}\right)$ & $8.4[5.2 ; 13.7]$ & $9.0[5.9 ; 10.5]$ \\
\hline $\mathrm{RV}$ diastolic area $Z$-score & $0.3[-0.3 ; 1.5]$ & $-0.1[-1 ; 0.4]$ \\
\hline RVOT pressure gradient (mmHg) & $5.0[5.0 ; 7.5]$ & $22.0[11.8 ; 38.0]$ \\
\hline $\mathrm{RV}$ fractional area change $(\%)$ & $35.7[30.6 ; 47.2]$ & $43.7[35.9 ; 47.5]$ \\
\hline $\mathrm{RV}$ fractional area change $Z$-score & $-0.5[-0.8 ; 0.8]$ & $0.8[-0.2 ; 1.5]$ \\
\hline RV global systolic strain & $-16.3[-11.3 ;-17.7]$ & $-17.5[-15.6 ;-19.7]$ \\
\hline TAPSE $(\mathrm{mm})$ & $10[9.0 ; 12.5]$ & $11.5[9.0 ; 13.3]$ \\
\hline TAPSE $Z$-Score & $-3.8[-5.5 ;-2.5]$ & $-4.8[-6.4 ;-2.9]$ \\
\hline Pulmonary valve diameter $Z$-score & $-1.7[-3.4 ;-0.37]$ & \\
\hline \multicolumn{3}{|l|}{ LV echocardiographic measurements } \\
\hline LVEDVi $\left(\mathrm{ml} / \mathrm{m}^{2}\right)$ & $36.9[29.9 ; 43.9]$ & $48.4[41.2 ; 61.7]$ \\
\hline LVEDV Z-score & $-1.7[-2.1 ;-1.2]$ & $-0.4[-1.2 ;-0.1]$ \\
\hline LVOT pressure gradient $(\mathrm{mmHg})$ & $65[55 ; 80]$ & $6[4 ; 10]$ \\
\hline LV mass index $\left(\mathrm{g} / \mathrm{m}^{2}\right)$ & $48.5[43.7 ; 58.1]$ & $61.3[56.3 ; 71.3]$ \\
\hline LV mass Z-score & $0.5[-0.3 ; 1.9]$ & $1.1[0.2 ; 3.4]$ \\
\hline LV mass/volume ratio & $1.5[1.1 ; 1.6]$ & $1.2[0.9 ; 1.4]$ \\
\hline $\operatorname{LV} \mathrm{EF}(\%)$ & $60[56 ; 64]$ & $56[49 ; 61]$ \\
\hline LV global systolic strain (\%) & $-21.2[-17.3 ;-24.2]$ & $-17.9[-15 ;-21.1]$ \\
\hline LV global systolic strain $Z$-score & $0.4[-1.9 ; 1.6]$ & $-1.4[-3.1 ; 0.9]$ \\
\hline Aortic valve diameter $Z$-score & $3.0[2.3 ; 4.6]$ & $2.8[0.9 ; 4.4]$ \\
\hline \multicolumn{3}{|l|}{ Invasive measurements } \\
\hline LV end-diastolic pressure $(\mathrm{mmHg})$ & $10[8 ; 12]$ & \\
\hline Systolic LV/RV pressure ratio & $1.00[0.99 ; 1.02]$ & \\
\hline
\end{tabular}

Data presented as median [interquartile range]

$E F$ ejection fraction, $L V$ left ventricle, $L V E D V$ left ventricular end-diastolic volume, $L V E D V i$ indexed left ventricular end-diastolic volume, $L V O T$ left ventricular outflow tract, $R V$ right ventricle, $R V O T$ right ventricular outflow tract, TAPSE tricuspid annular plane systolic excursion from re-operation did not differ significantly compared to the more complex procedures $[100 \%$ vs. $77 \%(95 \% \mathrm{CI}$ $43.9 ; 92.1), P=0.3$ and $85.7 \%$ (95\% CI $33.4 ; 99.8)$ vs. $68.2 \%$ (95\% CI 28.6;88.9), $P=0.8$, respectively. Figure 2]. Also, comparing patients with and without prior PAB, there was no significant difference concerning 5-year survival and freedom from reoperation rates $[100 \%$ vs. $75.9(95 \%$ CI 42.23;91.6), $P=0.2$ and $70 \%$ (95\% CI $22.5 ; 91.8)$ vs. $72 \%$ (95\% CI 23.8;92.8), $P=0.5$, respectively].

At last follow-up, all surviving patients were in NYHA/ modified Ross classification functional class I (15/22, 68\%) or II $(7 / 22,32 \%)$ and there was no case of LV failure occurring during follow-up.

\section{Echocardiographic Follow-Up Data}

The majority of patients exhibited good LV function and preserved LV global systolic strain at last follow-up although in general, LVEF decreased slightly but statistically significantly $(P=0.005$, Table 2$)$. Seven patients
(32\%) had mild (LVEF < 55\%) and one patient (5\%) moderate impairment of LV function (LVEF < 45\%) which was, however, stable during follow-up. Overall, LVEDV $Z$-scores increased significantly ( $P=0.005$, Table 2$)$. Aortic/neoaortic valve regurgitation was either absent/trivial $(13 / 22,59 \%)$ or mild $(9 / 22,41 \%)$. Also, MV incompetence was uncommon with only three patients (14\%) having mild regurgitation. Moreover, TV was competent in most patients $(77.3 \%)$ while only five $(22.7 \%)$ had mild regurgitation. No differences in any of these parameters were noticed between different surgical techniques (all $P>0.5$ ).

\section{Risk Factors for Early Failure After Anatomic Repair}

A multivariable regression analysis to identify potential risk factors (age, surgical method, prior PAB, relevant LVOTO, low LV mass) for early repair failure revealed no independent risk factors $(P=0.2-0.9$, Supplemental Table 3). 

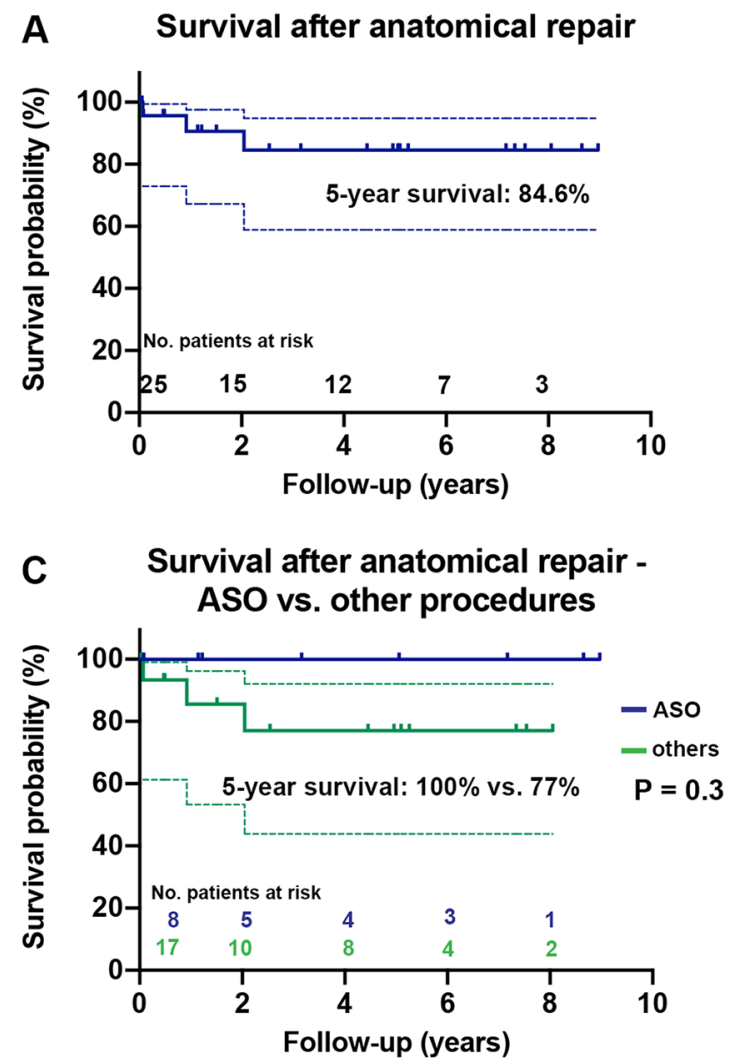

Fig. 2 Survival and freedom from reoperation estimates. KaplanMeier curves (solid lines) with 95\%-confidence intervals (dashed lines) depicting survival and freedom from reoperation in entire study

Table 3 Proposed eligibility criteria for cc-TGA patients to undergo anatomic repair

\begin{tabular}{ll}
\hline Parameter & Value \\
\hline LV EF\% & $\geq 50 \%$ \\
LV mass Z-Score & $\geq-2 ;<3$ \\
LVEDV Z-Score & $\geq-2.5$ \\
LV mass/volume ratio & $\geq 0.9 ; \leq 1.8$ \\
LV/RV pressure ratio & $\geq 0.9$ \\
\hline
\end{tabular}

$E F$ ejection fraction, $L V$ left ventricle, $L V E D V$ left ventricular enddiastolic volume, $R V$ right ventricle

\section{Discussion}

Patients with cc-TGA constitute a complex and heterogeneous cohort frequently associated with cardiac anomalies, anatomic variations and individual hemodynamic characteristics rendering the anatomic correction technically challenging. In our study, we demonstrate that excellent early and mid-term survival rates are achievable. This is
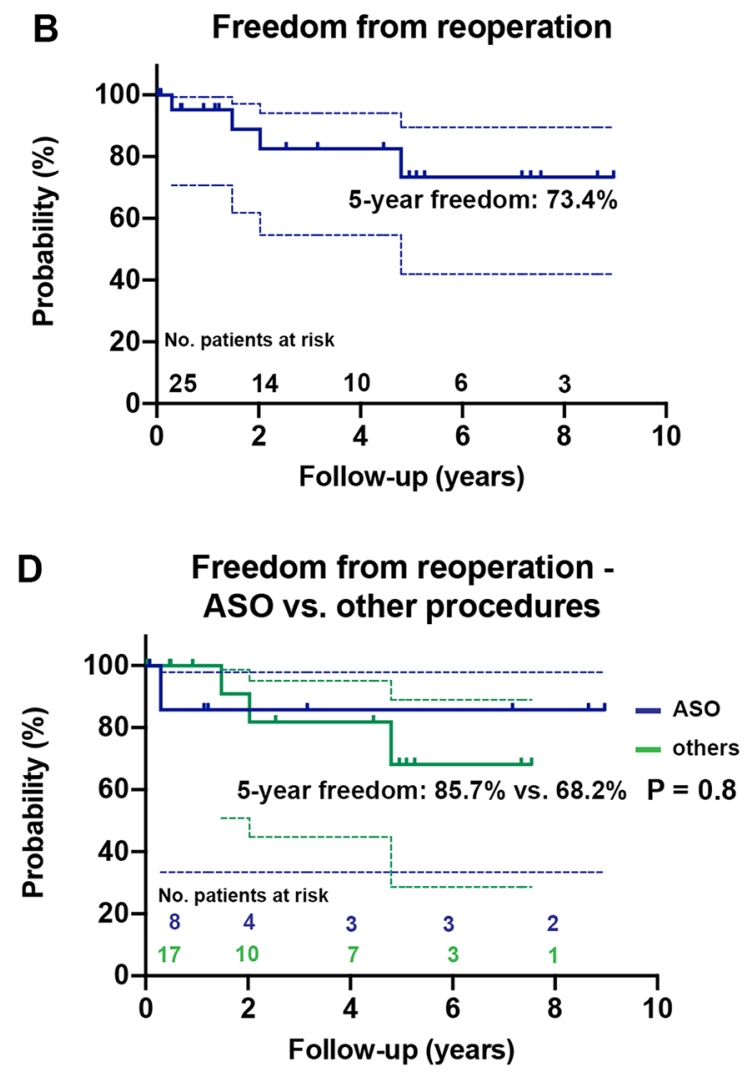

cohort (a, b) and anatomical repair with atrial stage switch and arterial switch operation (ASO) versus other procedures $(\mathbf{c}, \mathbf{d})$. The color image is available in the online version of the article

consistent with previous studies reporting 5-year survival rates varying between 75 and $95 \%[7,9,10]$.

To achieve favorable outcome after anatomic correction, careful and accurate selection of appropriate patients, optimal timing and surgical technique are clearly important. Several studies have proposed various criteria to assess eligibility of cc-TGA patients to undergo anatomic repair, mainly focusing on patient's age and morphologic LV function, pressure, mass and mass/volume ratio [8, 11-13, 15].

Age as factor influencing outcome and survival has been the focus of various studies, generally in respect of age limit for a meaningful re-training of the morphological LV, which has been reported to be of limited success beyond the age of 15 years $[8,15]$. It is however unclear, if such age limit is an appropriate selection criterion for anatomical correction if systemic pressure load of the morphological LV is already present. In our patient cohort, 2 patients were beyond this age limit at time of surgery. One patient (\#4) initially experienced favorable outcome after anatomical repair but unfortunately died 2 years later after reoperation for pulmonary heterograft stenosis. The second patient (\#10) had early repair failure. She displayed severely compromised biventricular function postoperatively, probably due to considerable 
myocardial hypertrophy not tolerating cardiopulmonary bypass. Our results suggest that age $>15$ years is not a contraindication for anatomic correction per se if $\mathrm{LV}$ volume and pressure lead are already present, but also emphasize the importance of careful patient selection in respect to additional criteria.

LV function and MV competence represent additional important factors to consider when evaluating a cc-TGA patient for anatomic correction. A normal LVEF (> 55\%) and MV regurgitation less than mild/moderate have been proposed as required by several groups $[11,12]$. In our cohort, four patients with favorable early outcome had mildly impaired LVEF (50-53\%) indicating that minor functional impairment does not represent a contraindication.

Several studies have focused on morphologic LV pressure in relation to systemic pressure as major criterion to determine suitability for anatomic correction and LV/RV pressure ratios ranging from $>70$ to $\geq 90 \%$ have been recommended $[8,11,12]$. All our patients had LV/RV pressure ratios of $\geq 90 \%$ and therefore our data does not substantiate conclusions regarding the suitability of lower LV pressure loads.

The most disputable criterion might be the suggested LV mass index required to be at least $45-50 \mathrm{~g} / \mathrm{m}^{2}$ [11]. In fact, seven of our patients with successful anatomic corrections (28\%) had values below $45 \mathrm{~g} / \mathrm{m}^{2}$ as determined by echocardiography. LV mass has a strong relationship to body surface area, however, the relation is non-linear and accordingly, reference values for echocardiographically determined LV mass index are not constant [21]. It would thus seem advisable to establish thresholds in relation to normal values accounting for growth-dependent changes using $Z$-scores. LV mass $Z$-Scores of these patients were normal in six $(-1.3$ to -0.1$)$ and borderline abnormal in one patient $(-2.1)$, respectively. The two patients with early repair failure both had normal or above normal LV mass Z-scores (-1.3 patient \#22 and 4.1 patient \#10, respectively), emphasizing that LV mass alone seems inadequate to determine suitability. Moreover, significant LV hypertrophy as observed in one of these patients (\#10), might represent a risk factor for surgical failure hitherto not sufficiently taken into consideration.

Furthermore, small LV dimensions may constitute a possible risk factor for early LV failure not adequately appreciated in previous recommendations. While previous studies focused on sufficient LV mass in relationship to volume suggesting a lower limit for mass/volume ratio of $0.9-1.5$ $[12,16]$, the possible negative impact of postoperative LV systolic but also diastolic dysfunction which might be caused by small LV dimensions and/or hypertrophy are not reflected by this threshold [12]. It might be reasonable to additionally implement upper thresholds for LV mass/volume ratio as well as LV mass in the considerations when evaluating patients for anatomic repair. In our cohort, all patients met the previously suggested criterion of mass/volume ratio $>0.9$. Patients however generally tended to have $\mathrm{LV}$ volumes in the lower range of the normal spectrum with a median LVEDV Z-score of -1.7 [-2.1;-1.2] despite most patients having an unrestrictive VSD with systemic pressure load and volume load. Nine patients (36\%) had abnormally low $Z$-scores $<-2$ prior to surgery. The patient (\#22) who experienced early postoperative LV failure had the lowest LVEDV Z-score in our cohort with-2.93. Retrospectively, we would judge that this patient most likely would have required longer LV training with possibly additional volume load by the creation of an interatrial communication to enhance LV volume load. Moreover, from out data we conclude that it may not generally be assumed that presence of a large unrestrictive VSD with LV pressure and volume load renders cc-TGA patients suitable candidates for repair in respect to sufficient LV muscle mass and volume development. Rather, these patients with cc-TGA and unrestrictive VSD likewise require a comprehensive and careful evaluation of their eligibility for anatomic repair.

As important finding of this study, a substantial number of our patients did not meet previously recommended criteria for "ideal" candidates for anatomic correction but nevertheless underwent successful anatomic repair. Out of 23 patients successfully operated, $10(44 \%)$ would have been classified as "unsuitable" candidates if these criteria were applied strictly $[8,11-13,15,16]$. Summarizing our data, we propose modified criteria to select patients suitable for anatomic correction which are tabulated in Table 3.

\section{Limitations}

Our study has several important limitations. Since this is a retrospective, single institutional non-interventional study, patients were managed individually and moreover, evaluation and treatment protocols changed during the study period. Echocardiographic assessment of important parameters regarding ventricular function, dimensions and mass has some significant technical limitations. Suboptimal image acquisition as well as abnormal ventricular geometry may represent considerable sources of error regarding measurements. As additional important note, reference values and corresponding $Z$-scores for pediatric cardiac structures vary substantially according to measuring methods and imaging modalities and are generally derived from normal anatomies. Future studies should preferably employ standardized imaging protocols considering these issues. Moreover, it might be recommendable to favor more accurate and less variable imaging modalities such as cardiac magnetic resonance imaging to assess suitability for anatomic correction, which was, however, only inconsistently performed in our study and therefore not analyzed. 
In addition, our small cohort size and short follow-up interval clearly limit the possibilities of statistical analyses.

\section{Conclusions}

Our study demonstrates that anatomic correction for cc-TGA patients can be performed with good early and mid-term outcomes but also indicates that previously recommended eligibility criteria may require reconsideration. We suggest modifications of these criteria using LV mass and volume $Z$-scores. These modified selection criteria will have to be validated in future studies.

Supplementary Information The online version contains supplementary material available at https://doi.org/10.1007/s00246-022-02841-z.

Author Contributions VHMW: Formal analysis, investigation, data curation, writing — original draft, writing—review \& editing; PK: Formal analysis, investigation, data curation, writing-original draft, writing — review \& editing; PM: investigation, writing — review \& editing; OR: investigation, writing-review \& editing; MC: investigation, writing — review \& editing; SO: investigation, writing—review \& editing; MH: Conceptualization, supervision; Felix Berger: Conceptualization, supervision, writing - review \& editing; JP: Conceptualization, supervision, writing—review \& editing.

Funding Open Access funding enabled and organized by Projekt DEAL. No funding was received for conducting this study.

\section{Declarations}

Conflict of interest The authors have no relevant financial or non-financial interests to disclose.

Ethical Approval The study was approved by the institutional ethics committee (EA2/165/19), the requirement of written consent was waived.

Open Access This article is licensed under a Creative Commons Attribution 4.0 International License, which permits use, sharing, adaptation, distribution and reproduction in any medium or format, as long as you give appropriate credit to the original author(s) and the source, provide a link to the Creative Commons licence, and indicate if changes were made. The images or other third party material in this article are included in the article's Creative Commons licence, unless indicated otherwise in a credit line to the material. If material is not included in the article's Creative Commons licence and your intended use is not permitted by statutory regulation or exceeds the permitted use, you will need to obtain permission directly from the copyright holder. To view a copy of this licence, visit http://creativecommons.org/licenses/by/4.0/.

\section{References}

1. Wallis GA, Debich-Spicer D, Anderson RH (2011) Congenitally corrected transposition. Orphanet J Rare Dis 6:22. https://doi.org/ $10.1186 / 1750-1172-6-22$
2. Murtuza B, Barron DJ, Stumper O, Stickley J, Eaton D, Jones TJ, Brawn WJ (2011) Anatomic repair for congenitally corrected transposition of the great arteries: a single-institution 19-year experience. J Thorac Cardiovasc Surg 142(6):1348-57 e1. https:// doi.org/10.1016/j.jtcvs.2011.08.016

3. Ilbawi MN, DeLeon SY, Backer CL, Duffy CE, Muster AJ, Zales VR, Paul MH, Idriss FS (1990) An alternative approach to the surgical management of physiologically corrected transposition with ventricular septal defect and pulmonary stenosis or atresia. J Thorac Cardiovasc Surg 100(3):410-415

4. Nikaidoh H (1984) Aortic translocation and biventricular outflow tract reconstruction. A new surgical repair for transposition of the great arteries associated with ventricular septal defect and pulmonary stenosis. J Thorac Cardiovasc Surg 88(3):365-372

5. Mair R, Sames-Dolzer E, Vondrys D, Lechner E, Tulzer G (2006) En bloc rotation of the truncus arteriosus-an option for anatomic repair of transposition of the great arteries, ventricular septal defect, and left ventricular outflow tract obstruction. J Thorac Cardiovasc Surg 131(3):740-741. https://doi.org/10.1016/j.jtcvs. 2005.10.047

6. Yamagishi M, Shuntoh K, Matsushita T, Fujiwara K, Shinkawa T, Miyazaki T, Kitamura N (2003) Half-turned truncal switch operation for complete transposition of the great arteries with ventricular septal defect and pulmonary stenosis. J Thorac Cardiovasc Surg 125(4):966-968. https://doi.org/10.1067/mtc.2003.33

7. Hraska V, Vergnat M, Zartner P, Hart C, Suchowerskyj P, Bierbach B, Schindler E, Schneider M, Asfour B (2017) Promising outcome of anatomic correction of corrected transposition of the great arteries. Ann Thorac Surg 104(2):650-656. https://doi.org/ 10.1016/j.athoracsur.2017.04.050

8. Hiramatsu T, Matsumura G, Konuma T, Yamazaki K, Kurosawa H, Imai Y (2012) Long-term prognosis of double-switch operation for congenitally corrected transposition of the great arteries. Eur J Cardiothorac Surg 42(6):1004-1008. https://doi.org/10.1093/ ejcts/ezs 118

9. Hraska V, Duncan BW, Mayer JE Jr, Freed M, del Nido PJ, Jonas RA (2005) Long-term outcome of surgically treated patients with corrected transposition of the great arteries. J Thorac Cardiovasc Surg 129(1):182-191. https://doi.org/10.1016/j.jtcvs.2004.02.046

10. Brizard CP, Lee A, Zannino D, Davis AM, Fricke TA, d'Udekem Y, Konstantinov IE, Brink J, Cheung MMH (2017) Long-term results of anatomic correction for congenitally corrected transposition of the great arteries: a 19-year experience. J Thorac Cardiovasc Surg 154(1):256-265 e4. https://doi.org/10.1016/j.jtcvs. 2017.03.072

11. Ibrahimiye AN, Mainwaring RD, Patrick WL, Downey L, Yarlagadda V, Hanley FL (2017) Left ventricular retraining and double switch in patients with congenitally corrected transposition of the great arteries. World J Pediatr Congenit Heart Surg 8(2):203-209. https://doi.org/10.1177/2150135116683939

12. Myers PO, del Nido PJ, Geva T, Bautista-Hernandez V, Chen P, Mayer JE Jr, Emani SM (2013) Impact of age and duration of banding on left ventricular preparation before anatomic repair for congenitally corrected transposition of the great arteries. Ann Thorac Surg 96(2):603-610. https://doi.org/10.1016/j.athoracsur. 2013.03.096

13. Zartner PA, Schneider MB, Asfour B, Hraska V (2016) Enhanced left ventricular training in corrected transposition of the great arteries by increasing the preload. Eur J Cardiothorac Surg 49(6):1571-1576. https://doi.org/10.1093/ejcts/ezv416

14. Rastelli GC (1969) A new approach to "anatomic" repair of transposition of the great arteries. Mayo Clin Proc 44(1):1-12

15. Winlaw DS, McGuirk SP, Balmer C, Langley SM, Griselli M, Stumper O, De Giovanni JV, Wright JG, Thorne S, Barron DJ, Brawn WJ (2005) Intention-to-treat analysis of pulmonary artery banding in conditions with a morphological right ventricle in the 
systemic circulation with a view to anatomic biventricular repair. Circulation 111(4):405-411. https://doi.org/10.1161/01.CIR. 0000153355.92687.FA

16. Ly M, Belli E, Leobon B, Kortas C, Grollmuss OE, Piot D, Planche C, Serraf A (2009) Results of the double switch operation for congenitally corrected transposition of the great arteries. Eur J Cardiothorac Surg 35(5):879-883. https://doi.org/10.1016/j. ejcts.2009.01.051

17. Ross RD (2012) The Ross classification for heart failure in children after 25 years: a review and an age-stratified revision. Pediatr Cardiol 33(8):1295-1300. https://doi.org/10.1007/ s00246-012-0306-8

18. Lopez L, Colan SD, Frommelt PC, Ensing GJ, Kendall K, Younoszai AK, Lai WW, Geva T (2010) Recommendations for quantification methods during the performance of a pediatric echocardiogram: a report from the Pediatric Measurements Writing Group of the American Society of Echocardiography Pediatric and Congenital Heart Disease Council. J Am Soc Echocardiogr 23(5):465-495. https://doi.org/10.1016/j.echo.2010.03.019

19. Dallaire F, Slorach C, Bradley T, Hui W, Sarkola T, Friedberg MK, Jaeggi E, Dragulescu A, Mahmud FH, Daneman D, Mertens $\mathrm{L}$ (2016) Pediatric reference values and $\mathrm{Z}$ score equations for left ventricular systolic strain measured by two-dimensional speckletracking echocardiography. J Am Soc Echocardiogr 29(8):786-793 e8. https://doi.org/10.1016/j.echo.2016.03.018

20. Lee JH, Park JH (2018) Strain analysis of the right ventricle using two-dimensional echocardiography. J Cardiovasc Imaging 26(3):111-124. https://doi.org/10.4250/jcvi.2018.26.e11

21. Lopez L, Colan S, Stylianou M, Granger S, Trachtenberg F, Frommelt P, Pearson G, Camarda J, Cnota J, Cohen M, Dragulescu A,
Frommelt M, Garuba O, Johnson T, Lai W, Mahgerefteh J, Pignatelli R, Prakash A, Sachdeva R, Soriano B, Soslow J, Spurney C, Srivastava S, Taylor C, Thankavel P, van der Velde M, Minich L, Pediatric Heart Network I (2017) Relationship of echocardiographic $\mathrm{Z}$ scores adjusted for body surface area to age, sex, race, and ethnicity: the Pediatric Heart Network Normal Echocardiogram Database. Circ Cardiovasc Imaging. https://doi.org/10.1161/ CIRCIMAGING.117.006979

22. Koestenberger M, Nagel B, Ravekes W, Avian A, Burmas A, Grangl G, Cvirn G, Gamillscheg A (2014) Reference values and calculation of z-scores of echocardiographic measurements of the normal pediatric right ventricle. Am J Cardiol 114(10):15901598. https://doi.org/10.1016/j.amjcard.2014.08.028

23. Koestenberger M, Ravekes W, Everett AD, Stueger HP, Heinzl B, Gamillscheg A, Cvirn G, Boysen A, Fandl A, Nagel B (2009) Right ventricular function in infants, children and adolescents: reference values of the tricuspid annular plane systolic excursion (TAPSE) in 640 healthy patients and calculation of $\mathrm{z}$ score values. J Am Soc Echocardiogr 22(6):715-719. https://doi.org/10.1016/j. echo.2009.03.026

24. McCloud AK, Lowisz J, Roberson DA, Lefaiver CA, Penk JS (2019) Semi-automated speckle-tracking for quantitative right ventricular assessment in children and adolescents. Cardiol Young 29(9):1149-1159. https://doi.org/10.1017/S1047951119001641

Publisher's Note Springer Nature remains neutral with regard to jurisdictional claims in published maps and institutional affiliations. 